\title{
How to Improve Pronunciation? An In-depth Contrastive Investigation of Sound-spelling Systems in English and Persian
}

\author{
Seyyed Mohammad Ali soozandehfar \\ Dept. of Foreign Languages and Linguistics, Shiraz University, Shiraz, Iran \\ Email: soozandehfar@yahoo.com \\ Marzieh Souzandehfar \\ Dept. of Foreign Languages and Linguistics, Shiraz University, Shiraz, Iran
}

\begin{abstract}
This study is a contrastive investigation between English and Persian sound-spelling systems in which the problematic areas for both English and Persian learners have been identified. Firstly, the researcher has determined the common base between the two languages, i.e. the structural phonology, and has postulated it as the tertium comparationis of the study. Through an in-depth examining of the sound-spelling characteristics of each language, the study has gone through the description stage. After that, the comparable features have been identified in the juxtaposition stage. Then, in the comparison stage, the detailed comparison and contrast of the two languages have been made in terms of the juxtaposed sound-spelling features. Finally, the EFL learners' pronunciation problems have been analyzed for the prediction stage. The results have indicated that there are a number of regularities and irregularities which can be problematic for both English and Persian learners, especially for non-native speakers learning English. Moreover, this study has some implications in TEFL for teachers to know and consider such problematic areas and teach the students these inconsistencies so as to reduce such preventative factors in their learning.
\end{abstract}

Index Terms - contrastive analysis, pronunciation, sound, spelling

\section{INTRODUCTION}

Pronunciation involves far more than individual sounds. Word stress, sentence stress, intonation, and word linking all influence the sounds of spoken English, not to mention the way we often slur words and phrases together in casual speech. "What are you going to do?" becomes "Waddaya gonna do?" English pronunciation involves too many complexities for EFL learners to strive for a complete elimination of accent, but improving pronunciation will boost self esteem, facilitate communication, and possibly lead to a better job or at least more respect in the workplace. Effective communication is of greatest importance, so one must choose first to work on problems that significantly hinder communication and then refer to features in terms of accuracy. One should remember that the students also need to learn strategies for dealing with misunderstandings, since native pronunciation is for most an unrealistic goal.

Therefore, the English spelling system has both regularities and irregularities which can be problematic for nonnative speakers learning English. But it is possible for the teachers to know them and teach the students the inconsistencies. This paper tends to have a survey on the similarities and differences between English and Persian sound-spelling and identifies the problematic areas for both English and Persian learners.

Objective of the Study

This study is a contrastive investigation between English and Persian sound-spelling systems, in which, first, the sound-spelling system of each language has been described separately, and second, a number of both consistencies and inconsistencies between the Persian and English sound-spelling systems have been explored. Moreover, through this investigation, the study has analyzed some problematic areas of pronunciation in Iranian EFL learners pronouncing a number of pre-determined vocabularies, containing some inconsistencies in the sound-spelling features, so as to specify the sources of such pronunciation problems, and therefore, to be helpful for both EFL learners and teachers. In particular, the following questions have been answered through the present study:

1. What are the characteristics of the Persian sound-spelling system?

2. What are the characteristics of the English sound-spelling system?

3. What are the consistencies and inconsistencies between the English and Persian sound-spelling systems?

4. What are the sources of pronunciation problems in Iranian EFL learners at the beginner, intermediate, and advanced levels?

\section{LITERATURE REVIEW}




\section{A. Contrastive Analysis and Phonology}

In human language, a phoneme (from the Greek: $\varphi \omega ́ v \eta \mu \alpha$, phōnēma, "a sound uttered") is the smallest posited linguistically-distinctive unit of sound. Phonemes carry no semantic content themselves. In theoretical terms, phonemes are not the physical segments themselves, but cognitive abstractions or categorizations of them. A morpheme is the smallest structural unit with meaning.

In effect, a phoneme is a group of slightly different sounds which are all perceived to have the same function by speakers of the language in question. An example of a phoneme is the /k/ sound in the words "kit" and "krill." (In transcription, phonemes are placed between slashes, as here.) Even though most native speakers do not notice, in most dialects, the "k" sounds in each of these words are actually pronounced differently: they are different speech sounds, or phones (which, in transcription, are placed in square brackets). In our example, the /k/ in "kit" is aspirated, $\left[\mathrm{k}^{\mathrm{h}}\right]$, while the $/ \mathrm{k} /$ in "krill" is not, [k]. The reason why these different sounds are nonetheless considered to belong to the same phoneme in English is that if an English-speaker used one instead of the other, the meaning of the word would not change: saying $\left[\mathrm{k}^{\mathrm{h}}\right]$ in "krill" might sound odd, but the word would still be recognized. By contrast, some other sounds could be substituted which would cause a change in meaning, producing words like "frill" (substituting /f/), "grill" (substituting /g/) and "shrill" (substituting / / /). These other sounds (/f/, /g/ and / / /) are, in English, different phonemes. In some languages, however, $\left[\mathrm{k}^{\mathrm{h}}\right]$ and $[\mathrm{k}]$ are different phonemes, and are perceived as such by the speakers of those languages. Thus, in Icelandic, $/ \mathrm{k}^{\mathrm{h}} /$ is the first sound of "kátur" meaning "cheerful", while / $\mathrm{k} /$ is the first sound of "gátur" meaning "riddles."

In many languages, each letter in the spelling system represents one phoneme. However, in English spelling there is a very poor match between spelling and phonemes. For example, the two letters "sh" represent the single phoneme $/ \mathrm{S} /$, while the letters " $\mathrm{k}$ " and "c" can both represent the phoneme /k/ (as in "kit" and "cat"). Phones that belong to the same phoneme, such as $[t]$ and $\left[\mathrm{t}^{\mathrm{h}}\right]$ for English / $\mathrm{t} /$, are called allophones. A common test to determine whether two phones are allophones or separate phonemes rely on finding minimal pairs: words that differ by only the phones in question. For example, the words "tip" and "dip" illustrate that [t] and [d] are separate phonemes, /t/ and /d/, in English, whereas the lack of such a contrast in Korean $\left(/ \mathrm{t}^{\mathrm{h}}\right.$ ata/ is pronounced [ $\mathrm{t}^{\mathrm{h}}$ ada], for example) indicates that in this language they are allophones of a phoneme $/ \mathrm{t} /$.

In sign languages, the basic elements of gesture and location were formerly called "cheremes" (or cheiremes), but general usage changed to phoneme. Tonic phonemes are sometimes called "tonemes," and timing phonemes "chronemes" (Crystal, 2003). Some linguists, such as Roman Jakobson (1987), Morris Halle (1986), and Noam Chomsky (1991), consider phonemes to be further decomposable into features, such features being the true minimal constituents of language. Features overlap each other in time, as do suprasegmental phonemes in oral language and many phonemes in sign languages. Features could be designated as acoustic (Jakobson, 1987) or articulatory (Halle, 1986; Chomsky, 1991) in nature.

\section{B. Contrastive Analysis, Orthography, and Phonological Processing Skill}

Spelling is the writing of a word or words with all necessary letters and diacritics present in an accepted standard order. It is on of the elements of orthography and a prescriptive element of language. It makes lots of problems even for educated people. Snow et al. (2005) describes the importance of spelling by saying, "Spelling and reading build and rely on the same mental representation of a word. Knowing the spelling of a word makes the representation of sturdy and accessible for fluent reading." Most of the European languages use Latin script and they may differ in pronunciation of some letters such as /r/ and /l/. These differences show themselves more when it comes to non-Roman alphabets such as Japanese, Arabic and Persian. Spelling of the words has an important role in reading and writing and consequently in meaning understanding. In addition, word identification and spelling depends on skills such as orthographic processing and phonological skills.

Phonological processing skill has a great to do with the child's procedural knowledge about grapheme-to-phoneme correspondence rules. They provide the ability to form, store, and access the orthographic representation of words or meaningful parts of words (Stanovich and West, 1989). In reading process, children firstly depend on sound letter correspondence and when there is inconsistency with the letter and its representative sound, it makes difficulty for them, but later on, in the text stages, children learn to use phonological information to read words (Arab Moghaddam and Senechal, 2001).

Hanna et al. (1966) counted the probability of spelling a word correctly if one applies the letter string that most often correspond to the phoneme. When getting repeated exposure to the written word people begin to develop an orthographic representation in memory that contains the words' spelling as a kind of code.

\section{The Effect of Orthographic Complexity}

The effect of orthographic regularity has been widely studied (Sprenger-Charolles, Siegel, Béchennec, and Serniclaes, 2003; Waters, Bruck, and Seidenberg, 1985). Orthographic regularity refers to the way in which a language associates letters to sounds. To learn how to read and write, the child must acquire detailed orthographic representations of regular 
and irregular words and access them globally (Frith, 1985, 1986). Regular words have straightforward relationships between graphemes and phonemes, like camera $=/ \mathrm{kamera} /$. They can be read and/or written correctly by applying analytic grapho-phonological conversion mechanisms. Irregular words require global processing and can only be read or written by accessing orthographic representations. To acquire irregular words, the child has to be aware of certain spelling peculiarities, e.g. the "e" in "femme" is pronounced /a/ (/fam/) instead of /e/. In the present study, we also investigated whether the processing of these orthographic peculiarities constitutes a cognitive load in handwriting production during written language acquisition. Bloemsaat, Van Galen and Meulenbroek (2003) have shown that orthographic irregularity slows down performance when typewriting Dutch words. There was an increase in preparation time and typing time. In line with this study, we hypothesized that when acquiring irregular words, orthographic irregularities constitute a supplementary processing load that results in an increase in movement time at the location of the irregularity. In our study, the orthographic irregularity was located at the beginning, middle or end of words acquired early or late. If the child is familiar with the word, he/she can write it down by recovering information from the corresponding orthographic representations. In this case, the processing of irregular and regular words should be the same and yield no duration differences for words acquired early. A different mechanism operates when writing unfamiliar. The child applies a phonological recoding mechanism that works successfully when writing regular words. But, when the child has to write an unfamiliar irregular word, he/she has to memorize the spelling of the whole word and remember the identity and location of the orthographic irregularity. This operation constitutes a supplementary cognitive load that results in an increase in production time. We expected orthographic irregularity to affect first graders more than second graders. Second graders have been more exposed to written language than first graders, so they should have more spelling information stored in memory and therefore recover the spelling of regular and irregular words globally rather than analytically (Share, 1995, 1999).

\section{Error Analysis}

Error analysis, offered as an alternative to contrastive analysis, has its value in the classroom research. Whereas contrastive analysis, which may be least predictive at the syntactic level and at early stages of language learning (Brown, 1994), allows for prediction of the difficulties involved in acquiring a second language (Richards, 1974); error analysis emphasizing "the significance of errors in learners' interlanguage system" (Brown, 1994) may be carried out directly for pedagogic purposes (Ellis, 1995; Richards et al., 1993).

Because of the fact that contrastive analysis does not predict all learner difficulties and differences, Corder (1971) and Selinker (1972) considered L2 as a distinct system called "interlanguage." In addition to this, the idea of L1 interference on L2, has given rise to many studies of interlanguage phonology (Jenkins 2000). Brown, Deterding, and Low (2000), for example, investigated a range of differences between Singaporean and British English, including discourse intonation, pitch range, and lexical stress. Hung $(2000,2002)$ uses a contrastive methodology to specify his phonology of Hong Kong English. Deterding and Poedjosoedarmo (1998) is a research-based reference work for teachers, determining both details of the segmental and suprasegmental features of a wide range of different Southeast Asian languages and English (Jenkins, 2004).

Although there are so many studies on error analysis and interlanguage phonology, such studies are few when it comes to the English used by Persian students. Only a few works are available, such as Yarmohammadi's (2000; 2002) two books: The first one aiming at contrasting the phonological systems of English and Persian for pedagogical purposes (2000), and the second one, which is more complete, investigating the sources of syntactic, lexical, and phonological problems of Iranian English learners through a contrastive analysis of Persian and English (2002). However, the paucity of such research is obvious in an EFL context like Iran where there is no exposure to English native speakers.

\section{METHOD}

\section{A. Participants}

The main participants of the present study were three Iranian speakers of English as a foreign language at the beginner, intermediate, and advanced levels from Navid Institute.

Also, during the investigation of the study, the researcher has consulted two professors at Shiraz University, one instructor at SULC (Shiraz University Language Center), and two instructors at Navid institute. It should be mentioned that the very two professors teach Contrastive Linguistics at Shiraz University and are somewhat experienced in this field. Also, the above-mentioned instructors are very much familiar with contrastive linguistics and they have passed some courses in this field.

\section{B. Instruments}

- Cambridge Advanced Learners' Dictionary (2004);

- Oxford Advanced Learners' Dictionary (2005);

- A Dictionary of English Affixes and Combining Forms (Badie, 2006); 
-A corpus-based list of English vocabularies; the types of vocabularies in these lists were selected randomly based on the model of Awedyk (1974); this model is a syntagmatic phonological model of contrastive linguistics which contains the following structures, based on which different types of vocabulary were selected:

- Structures of nuclei

- Structure of the onset

- Structure of the coda

- Structure of the interlude

- Three beginner, intermediate, and advanced short passages.

- A sound-recorder set for recording the pronunciations and interviews of the participants.

\section{Procedures}

\section{Data Collection Procedure}

The data was collected through an interview with three Iranian EFL learners which consisted of four parts. First the learners were asked to introduce themselves briefly. Then, they were asked to read aloud a number of English words, phrases, and sentences in line with their level of proficiency, chosen randomly from a corpus-based list based on Awedyk's (1974) syntagmatic phonological model. In the next part, they were given a short passage to be read silently in five minutes and to give a summary of that passage. Finally, they were asked to read the passage aloud. Therefore, the sample contains both spontaneous speech and reading aloud pronunciation.

\section{Data Analysis Procedure}

First of all, in cross-language comparisons, the choice of tertium comparationis is a determining factor in establishing similarities and differences between the phenomena compared (Lipinska, 1975; Fisiak et al., 1978). In terms of phonological and lexical contrastive studies, the type of tertium comparationis is substantive insofar as it is connected with the material substance outside language, with which language is joined through its phonological interface, on the one hand, and through its semantic interface, on the other (Hjelmslev, 1961). Therefore, based on this and also on the basis of what Krzeszowski (1990) states, in the case of the present study, acoustic, articulatory, and, in principle, auditory phenomena provide the substantive tertium comparationis.

Moreover, the general sketch or the blue print of this study is based on the four classical steps in contrasting two language systems (Yarmohammadi and Rashidi, 2009): description, juxtaposition, comparison, and prediction.

According to Krzeszowski (1990), contrastive studies must be founded on independent descriptions of the relevant items of the languages to be compared in the same theoretical framework. Therefore, the present study has first described the sound-spelling system of the Persian and English languages separately within the descriptive framework of structural phonology, leading to specifications of a number of Persian-specific and English-specific features for juxtaposition, in which some of these features were selected to be compared. Then, in the comparison stage, the actual comparison and contrast of the sound-spelling systems in Persian and English were performed based on the very features selected in the juxtaposition stage, explicitly illustrating several similarities and differences between Persian and English.

Finally, on the basis of such comparison and contrast, further analyses were performed on the very three EFL learners' pronunciation errors observed in their interviews in order to determine the sources of such errors, so as to reach the last stage of contrastive analysis, i.e. the prediction stage. In this last stage, based on the specified sources, the study has made some predictions in the process of EFL pronunciation learning along with some implications and suggestions for EFL learners and teachers in the form of a trouble-shooting manual, which is actually in line with what Fisiak (1975) stresses regarding the relevance of contrastive studies to pedagogical purposes, i.e. they should be pedagogically oriented. Therefore, the analysis of this study consists of five parts:

1) Persian sound-spelling description;

2) English sound-spelling description;

3) Juxtaposition of Persian and English sound-spelling features;

4) Comparison and contrast of Persian and English sound-spelling juxtaposed features;

5) Analyzing the pronunciation errors of the EFL learners at the three levels of beginner, intermediate, and advanced.

a. Persian Sound-Spelling System

\section{History and Origins of Persian (Farsi) and Dari-Persian language}

Farsi or Persian is spoken today primarily in Iran, Afghanistan and Tajikistan, but was historically a more widely understood language in an area ranging from the Middle East to India. Significant populations of speakers in other Persian Gulf countries include Bahrain, Iraq, Oman, Republic of Yemen, and the United Arab Emirates as well as large communities around the world.

Total numbers of speakers is high: about $55 \%$ of Iran's population consists of Persian speakers; about $65 \%$ of the Tajikistan's population includes Tajik-Persian speakers: over 25\% of the Afghanistan's population refers to Dari-Persian speakers; and about $1 \%$ of the population of Pakistan deals with Dari-Persian speakers as well.

\section{Linguistic Affiliation}

Persian is a subgroup of West Iranian languages that include the closely related Persian languages of Dari and Tajik; the less closely related languages of Luri, Bakhtiari and Kumzari; and the non-Persian dialects of Fars Province. Other 
more distantly related languages of this group include Kurdish, spoken in Turkey, Iraq, and Iran; and Baluchi, spoken in Afghanistan, Iran, and Pakistan. Even more distantly related are languages of the East Iranian group, which includes, for example, Pashtu, spoken in Afghanistan; Ossete, spoken in North Ossetian, South Ossetian, and Caucusus of former USSR; and Yaghnobi, spoken in Tajikistan. Other Iranian languages of note are Old Persian and Avestan (the sacred language of the Zoroastrians for which texts exist from the 6th century B.C.).

West and East Iranian comprise the Iranian group of the Indo-Iranian branch of the Indo-European family of languages. Indo-Iranian languages are spoken in a wide area stretching from portions of eastern Turkey and eastern Iraq to western India. The other main division of Indo-Iranian, in addition to Iranian, is the Indo-Aryan languages; a group comprised of many languages of the Indian subcontinent, for example, Sanskrit, Hindi/Urdu, Bengali, Gujerati, Punjabi, and Sindhi.

\section{Linguistic Variation}

Scholars recognize three major dialect divisions of Persian: Farsi, or the Persian of Iran, Dari Persian of Afghanistan, and Tajik, a variant spoken Tajikistan in Central Asia. We treat Tajik as a separate language, however. Farsi and Dari have further dialectal variants, some with names that coincide with provincial names. All are more or less mutually intelligible.

Dari Persian, mainly spoken in Afghanistan, until recently, deferred to the Tehran standard as its model, and although there are clear phonological and morphological contrasts, due partly to the influence of neighbouring Turkic languages, Farsi and Dari Persian remain quite similar. The dialectal variation between Farsi and Dari has been described as analogous to that between European French and Canadian French. Dari is more conservative in maintaining vowel distinctions that have been lost in Farsi.

Luri and Bakhtiari, languages in the southwest part of Iran, are most closely related Farsi, but these are difficult for a speaker of the Tehran standard to understand. While speakers of Luri regard their speech as a dialect of Persian, speakers of Farsi do not agree. Judaic Persian, written in Hebrew characters and used by Jews throughout Iran, is close to the Persian standard in its written form. However, many Iranians of Jewish descent have left the country and no longer form a significant portion of the population.

\section{Orthography}

Persian in Iran and Afghanistan is written in a variety of the Arabic script called Perso-Arabic, which has some innovations to account for Persian phonological differences. This script came into use in Persia after the Islamic conquest in the seventh century. A variety of script forms: Nishki is a print type based closely on Arabic; Talik is a cultivated manuscript, with certain letters having reduced forms and others occasionally elongated in order to produce lines of equal length; and Shekesteh is also a manuscript, allowing for a greater variation of form and exhibiting extreme reduction of some letters.

\section{Linguistic Sketch}

The richly inflected morphological system of Old Iranian has been drastically reduced in Persian. The language has no grammatical gender or articles, but person and number distinctions are maintained. Nouns are marked for specificity: there is one marker in the singular and two in the plural. Objects of transitive verbs are marked by a suffix. The morphological features of Arabic words are preserved in loans, thus Persian shows "broken" plural formations, that is, a word may have two different plural forms.

Verbs are formed using one of two basic stems, present and past; aspect is as important as tense: all verbs are marked as perfective and imperfective. The latter is marked by means of prefixation. Both perfective and imperfective verb forms appear in three tenses: present, past and inferential past. The language has an aorist (a type of past tense), and has three moods: indicative, subjunctive, counterfactual. Passive is formed with the verb 'to become', and is not allowed with specified agents. Verbs agree with the subject in person and number. Persian verbs are normally compounds consisting of a noun and a verb.

Word order in Persian is Subject-Object-Verb although modifiers follow the nouns they modify and the language has prepositions. Persian distinguishes short and long vowels. Words are stressed on the last syllable.

Detailed descriptions of Persian orthography can be found in Khanlari (1979) and Baluch (2005). Persian language is transcribed by a modified version of the Semitic Arabic script. There are six spoken vowels in Persian. Three of the vowels are transcribed by actual letters of the alphabet (like English) and in the case of most words, they appear as a fixed part of the word's spelling (rather like English handwriting). The other three vowels are conveyed by diacritics placed above or below the word's spelling (see Figure 1 for examples of Persian words with vowel letter and with diacritic vowel). Persian, in its fully vowelized spelling in the direction of grapheme-to-phoneme correspondences, is very transparent (similar to Serbo-Croatian or Italian). Persian children learn to read and spell words in their fully vowelized format only in their first and second year textbooks. In practice, as can be seen in Figure 1, the diacritic vowels are almost always omitted from the word's spelling. Thus, one could identify a significant number of words in written Persian that have a consonantal spelling only. An illustration of this for a reader of English is the word dig spelled with dg. Of course, contrary to the significant graphic change to the spelling of dig without /i/, in the case of Persian, the only noticeable difference is removing a small diacritic from the top of a word's consonantal spelling. This is the situation with a significant number of words in Persian, henceforth referred to as opaque words because there are 
no vowels. In contrast, words in which the vowel is conveyed by the vowel letter(s) as a fixed part of the word spelling are referred to as transparent words.

An important point to note here is that in the Semitic scripts of Hebrew and Arabic, some vowels may also be omitted from print (see Koriat, 1984). However, contrary to both Hebrew and Arabic in which morphological rules help readers to decide on how the word may be pronounced (see Abu-Rabia, 1997; Koriat, 1984), Persian readers can resort mainly to contextual cues for disambiguation of such words. This is due to the fact that Persian has an affixal morphological system (see e.g., Baluch, 2005; Kashani, 1992). In view of the latter feature, a consonant only spelling in Persian may convey more than one totally unrelated meaning depending on different diacritic assignment. As an analogy, the English consonant string shp could be read as ship or shop. At other times, however, there is only one valid diacritic vowel that would give a correct pronunciation to the consonantal spelling. In the present study, only the latter type of words was used (i.e., consonant words with a unique possible pronunciation and meaning).

\section{b. English Sound-Spelling System}

English spelling should not be confused with the English language. English spelling is our traditional way of representing the English language in written form; there is no necessary connection between the spelling system and the language system. We spell English as we do because of a long history of decisions made by writers and printers. If the history of English-speaking society had been different, its spelling system would be different. The spelling of a sound is used to bring to mind the sound of a word. When <ee > is seen in print in the word three, the sound /i/ comes to the mind Learning to read, in the earliest stages, is the same as learning to associate particular spellings with particular sounds (Note that it was said particular spellings rather than particular letters; this is because not all sounds are spelled with single letters).

The English spelling system is an alphabet. An alphabet is a writing system in which the written symbols represent the phonemes (the word-building sounds) of the language, rather than, say, its syllables. For instance, the symbol $<\mathrm{p}>$ in English spelling represents the sound /p/, not a syllable such as /pa/ or /po/ (the main writing system of Japanese uses symbols to represent syllables like 'ma' or 'ko' rather than individual phonemes. Such a system is called a syllabary, not an alphabet.

Every writing system consists of an inventory of graphemes. A grapheme is a one of the set of symbols used to represent sounds -- it is a spelling of a particular sound. Each grapheme of a writing system is used to represent a unit of the language being written. In a syllabary, the graphemes stand for syllables; in an alphabet, the graphemes stand for phonemes. As seen above, English has numerous graphemes for the /i/ sound: me, see, seat, receive, machine, people.

The 26 letters of the English alphabet are the raw material used to create graphemes, which in turn are used to represent the phonemes of the language. For instance, the two letters $\langle\mathrm{s}\rangle$ and $\langle\mathrm{h}\rangle$ are combined into a digraph $\langle$ sh $\rangle$ to represent a single phoneme, the first sound of shoe, the middle sound of washer, etc. Letters themselves are not graphemes; they are the raw material for making graphemes. Don't let the fact that many English graphemes consist of one letter mislead you on this point. English has several grapheme types that go by traditional names in, for example, phonics instruction. These grapheme types are:

- Single-letter graphemes:

- Vowel letters: a e i o u, as in bat, set, fit, pot, nut

- Consonant letters: b c d f g h j k $1 \mathrm{~m} \mathrm{n} \mathrm{p} \mathrm{q} \mathrm{r} \mathrm{s} \mathrm{t} \mathrm{v} \mathrm{w} \mathrm{x} \mathrm{y} \mathrm{z} \mathrm{as} \mathrm{in} \mathrm{ace,} \mathrm{kit,} \mathrm{moon,} \mathrm{home,} \mathrm{etc.}$

- Double-letter graphemes:

- Vowel letters: ee, oo as in beet, cool. a, i, and u are only doubled in names derived from other languages such as Haas.

- Consonant letters: all consonants are frequently doubled except h, j, k, q, x, and y. Examples: apple, summer, toss, dizzy, etc.

- Letter-combination graphemes:

- Digraphs: Use of two different letters to spell a single sound, e.g., <th> for the first sound of three; <ch> as in chum, etc. In this case, the two letters make up a single grapheme, since they spell the sound together.

- Blends: Two letters that represent two sounds in sequence, as $\langle q u\rangle$ in queen $(\langle\mathrm{q}\rangle$ represents $/ \mathrm{k} /$ and $\langle\mathrm{u}\rangle$ represents $/ \mathrm{w} / ;<\mathrm{bl}\rangle$ as in black, etc. In this case, two graphemes are present: $\langle\mathrm{b}\rangle$ represents the $/ \mathrm{b} /$ of black, while $\langle\mathrm{l}\rangle$ represents its $/ 1 /$.

Silent letters, such as the <e> of time, the <k> of knee, and the <gh> of sight, are letters which appear in a word, but do not in themselves represent a sound. Most silent letters were pronounced at an earlier stage of the history of English, but then, though the sound was lost from the word, the spelling did not change. Many critics of English spelling decry the retention of these letters, but they do serve a purpose. In some cases, they differentiate one word from another in spelling, for instance knot vs. not. Other silent letters participate in what are called spelling patterns: they make up for the shortage of vowel symbols we suffer (English has about 16 vowel phonemes, but we use only 5 letters to represent these). This value of silent letters is discussed below.

People often speak of the frustrations and seeming chaos of English spelling, but it is in fact more systematic than meets the eye. English spelling does have many irregularities that are the product of history, but sometimes these help us see the meaning relation between words (as between sign and signature). The following paragraphs present just a few examples of sub-regularities in English spelling. 
- $\langle\mathrm{c}\rangle$ represents two sounds: /s/ and /k/ (both are present in $\langle$ accent $\rangle$ ). $\langle\mathrm{c}\rangle$ represents /s/ when it precedes $\langle\mathrm{e}\rangle,\langle\mathrm{i}\rangle$,

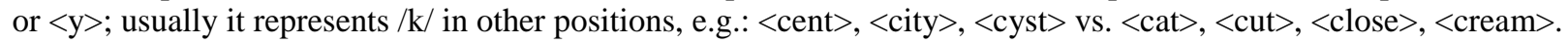

- The $/ \mathrm{k} /$ sound can be spelled in various ways: $\langle\mathrm{k}\rangle$ as in $\langle\mathrm{kid}\rangle,\langle\mathrm{c}\rangle$ as in $\langle\mathrm{cat}\rangle,\langle\mathrm{ck}\rangle$ as in $\langle$ back $\rangle,\langle\mathrm{ch}\rangle$ as in $\langle$ ache $\rangle,\langle q\rangle$ as in $\langle$ quite $\rangle$. One regularity in this variety of spellings is that $\langle$ ck $>$ cannot be used at the beginning of a word, but only in the middle or at the end. We find words such as $\langle$ tackle $\rangle$ and $\langle$ back $\rangle$, but not *ckat. (The asterisk $*$ means that the word it precedes violates a rule and is impossible within the system.)

- A double consonant is most often a cue to the pronunciation of a preceding vowel, especially in words of more than one syllable. Consider the pair <comma $\rangle$, $\langle$ coma $\rangle$. The double $\langle\mathrm{m}\rangle$ in the first word tells you that the $\langle 0\rangle$ is pronounced $/ \mathrm{a} /$; the single $\langle\mathrm{m}\rangle$ of the second tells you it is pronounced /o/. The pair $\langle$ tapping $\rangle$, $\langle$ taping $>$ illustrates the same principle, as do <super $>$, <supper $>$ and <biter $>$, <bitter $>$. Also, double consonants preserve the pronunciation of the vowel of a base word when a suffix is added: doubling the $\langle\mathrm{p}\rangle$ of $\langle$ tap $\rangle$ when - ing is added to produce $\langle$ tapping $\rangle$ preserves the pronunciation $/ \mathfrak{x} /$; if $\langle\mathrm{p}\rangle$ were not doubled, we would read $\langle$ taping $\rangle$. One other regularity about double consonants is that, while they often appear in the middle or at the end of a word, they never appear at the beginning;

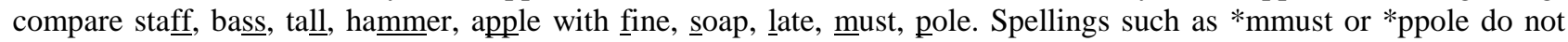
occur.

- Single consonants also provide cues to vowel pronunciation when contrasted with the use of a single consonant followed by silent <e>. Consider these pairs:

$$
\begin{aligned}
& \text { tap vs. tape } \\
& \text { mat vs. mate } \\
& \text { pip vs. pipe } \\
& \text { grim vs. grime } \\
& \text { met } \text { vs. mete } \\
& \text { mop vs. mope }
\end{aligned}
$$

Although the final $\langle\mathrm{e}\rangle$ is not pronounced and therefore might seem useless, it is actually an important cue that tells us how to pronounce the preceding vowel.

- Silent $\langle\mathrm{gh}\rangle$ and $\langle\mathrm{g}\rangle$ also signal how to pronounce the vowel in a word; compare $\langle$ fit $\rangle,\langle$ fight $\rangle,\langle$ mit $\rangle,\langle$ might $\rangle$, $<$ sit $>,<$ sight $>,<\sin >,<\operatorname{sign}>$.

This is a very brief description of how English spelling works. More can be found in Dechant (1969) and other books on "phonics."

\section{c. Juxtaposition of Persian and English sound-spelling features}

As James (1980) maintains, "the first thing we do [before actual comparison] is to make sure that we are comparing like with the like: this means that the two or more entities to be compared, while differing in some respect, must share certain attributes" (cited in Yarmohammadi and Rashidi, 2009). Therefore, according to what James (1980) alleges and also on the basis of the sound-spelling descriptions above related to each language, i.e. Persian and English, the following features have been juxtaposed based on which the actual comparison and contrast between the sound-spelling of the Persian and English languages have been performed in the next stage, i.e. the comparison proper:

1. Letter-sound correspondence

2. Base word pronunciation

3. Symbols in writing system

4. Spelling as a separative factor

5. Silent letters

6. Different position, different sound

7. Different spelling of the same sound

8. Criteria for spelling

9. Phoneme-grapheme correspondence

10. Sounds are more than letters

11. Spelling style

Now that in this section the juxtaposition has been done, i.e. the specification of "what is to be compared with what," the comparison proper can be performed.

\section{d. Comparison and contrast of Persian and English sound-spelling systems based on the juxtaposed features}

Feature 1: letter-sound correspondence

The first thing we can begin is that English writing system is an alphabetic one, that is, there is a correspondence between letters and individual sounds. But several of letters in English can have more than one sound value. So there is not always a strict one-to-one correspondence. Some letters are of single value such as (d, p, and m). Some of them can have two or more values like $\mathrm{c}$ as in cat and city. Persian writing system also is an alphabetic one and there is a correspondence between letters and individual sounds. However, there are some letters which represent the same sound as "س. س.ص. which stand just for /s/.

Feature 2: base word pronunciation

In English spelling system, a root or base is always spelt the same, e.g. in "sign" and "signal" the root is the same, but their pronunciations are different. In pure Persian there are a few roots and most of the roots we see are entered into 
Persian from Arabic such as: سليم.سالم.سلامت.سلام. They are pronounced according to their structural rules (e.g. subject, object) but the roots have unique spelling.

Feature 3: symbols in writing system

Some of the symbols used in the writing systems are combinations of two or more letters from alphabet e.g. "ph ' represents the sound /f/as 'fish' (like phase) -'th-' speaks for two sounds as in 'thick' and 'there' are pronounced. In Persian regarding خواهر in خواستن (xaahar) (sister) and (xastan) (to want) just ['] has the sound value.

Feature 4: spelling as a separative factor

Two words which are unrelated and different in meaning tend to be ' separated' visually for reader by their spelling

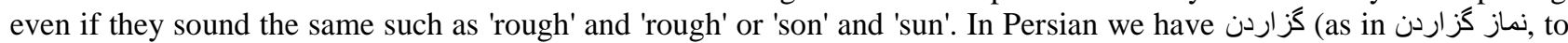

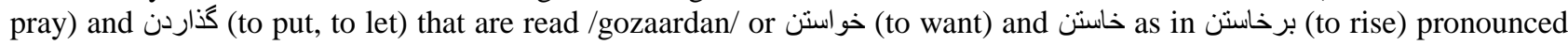
as /xaastan/.

Feature 5: silent letters

Some symbols are used to signal something about another symbol. They have no sound value themselves when they are functioning in this way. The clearest example is the letter ' $\mathrm{e}$ ' at the end of a word. However, it tells the reader something about the value of the preceding vowel letter. In word 'fete' the last 'e' is silent it shows that the first 'e' sounds /I/ as in 'feet'. In Persian there are 3 long vowels l l الى او او خوشحال.خوشبو.احرام : is pronounced a short vowel /u/. Other examples are خوش (ehraam), اهيانوس (ahrom), خرم (oghyaanoose).

Feature 6: different position, different sound

Position and surrounding are extremely important in English system. 'GH' can represent the sound /f/ if only it is at the end of the word. /Wh/ can come at the beginning of the word and '-ng-' at the end. In Persian this feature can exist

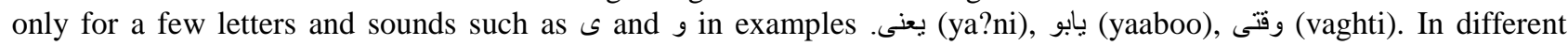
positions they sound different.

Feature 7: different spelling of the same sound

There are lots of different spelling for the same sound, e.g. ' $k$ ' can be spelled with several different letters and letter combinations, such as k (king), c (cat), ck (back), qu (queen), ch (chorus), and que (boutique). In Persian we have (سالم)

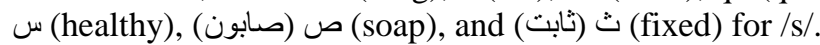

Feature 8: criteria for spelling

English words are spelled according to both their sounds (phonemes, such as $/ \mathrm{b} /$ ) and their meaningful parts (morphemes such as dict). In contrast, Persian uses single, consistent letters and letter combination for sounds. It is much stick to phonology representation. It seems easy to learn Persian, but if you come to a new word you can not get the meaning. In English, however, when there are Latin roots, you can find words like credible, credit, incredulous, and incredulity with the same underlying meaning of root, 'to believe'. However, they are different in sounds.

Feature 9: phoneme-grapheme correspondence

Speech sounds are spelled with single letters and/or combinations of up to four letters. The sound-symbol relationship is known as phoneme-grapheme correspondence. Graphemes may be composed of one to four letters, e.g. /a/ in cradle, may be, feign, weigh. In English we have just 26 letters to work with but about 40 phonemes and 250 graphemes. In Persian we have at most, two letter combinations to represent one sound such as [و أستن in خوا (to want).

Feature 10: sounds are more than letters

English has much more sounds than letters and these sounds may change according to context and influence each other. There are letters that have no corresponding sound in certain contexts as ' $g$ ' in 'sign'(sain), and 'though'. Or some of them transfer only a signal, not a sound e.g. double consonant. There are different words that can be categorized in this feature:

A) Letters that usually shorten the preceding vowel:

(Though-bought-brought), (نحهبان خود)

B) Words with silent letters:

(gnat-gnaw), (know-knee-knit), (isle-aisle-island), (should-could-would), (debt, doubt), (listen, softencastle)....(خواستن-خو (خر)

C) Words that look the same but are pronounced differently:

wind /wind/ (=moving air outdoors)...wind /waind/ (=twisting motion),

tear /tir/ (=drop of eye)...tear (t3r/ (=become torn),

جنگ/jang/ (=war).../jong/ (=miscellany),

نقا:naghl/ (=transfer, quotation).../noghl/ (=suger-plum),

os (mehr=affection; name of month $) . .($ mahr=wedding $g f i t) . . .($ mohr $=$ sign $)$

D) Words that look and sound the same but mean differently:

can (be able) (container)

lie (lie down) (don't tell lie, tell the truth)

شير(milk; tap; lion)

od(mehr=affection; name of a month)

خان(inn; khan) 
E). Words that have the same sounds but are spelled differently:

byte, bite, bight

here, hear

Their, they're, there

Err, heir, air

خوان/khaan/ = table), خان (=khan)

خرد/khord/ (=small), خورن (=ate)

Feature 11: $\underline{\text { spelling style }}$

English has both printing and writing, with capital and small letters. But Persian has only writing and letters always connect to each other. There is no capital letter in Persian but it can have as 4 different shapes, according to the place of

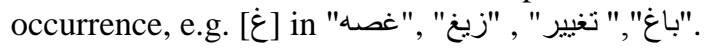

e. Analyzing the English pronunciation errors of the EFL learners at the three levels of beginner, intermediate, and advanced

This section actually supports the last stage of the present contrastive study, i.e. the prediction stage, which determines and predicts the type of English pronunciation errors that EFL learners make, along with the prediction of the sources of such erroneous pronunciations. In fact, error analysis, offered as an alternative to contrastive analysis, has its value in the classroom research. Although contrastive analysis, which may be least predictive at the syntactic level and at early stages of language learning (Brown, 1994), and does not take a distinct system called "interlanguage" into account, so that does not predict all learner difficulties and differences (Corder, 1971; and Selinker, 1972), it allows for prediction of the difficulties involved in acquiring a second language (Richards, 1974); and therefore, error analysis emphasizing "the significance of errors in learners' interlanguage system" (Brown, 1994) may be carried out directly for pedagogical purposes in contrastive studies (Ellis, 1995; and Richards et al., 1993).

So, this part of the study will show those problematic areas and features described, juxtaposed, and compared and contrasted in the preceding sections of the study in practice in the form of "error analysis." Therefore, the results of this section can be very helpful for both EFL learners and teachers to take into consideration.

The pronunciation problems are analyzed in five respects; problems with vowels, consonants, consonant clusters, stress, and intonation. Then each pronunciation problem is diagnosed. In the diagnosis phase, the following factors are taken into consideration as possible sources of the problems:

1. Momentary mental overload, distraction, fatigue, and haste which result in mistakes or performance lapses.

2. Mother Tongue Interference:

a) Negative Transfer

b) Positive Transfer

c) Non-existent linguistic Items: Items which exist in L2 but not in L1

3. Loan Words

4. Inherent Difficulties of the Target language:

The pronunciation, for example, we have:

chemist pronounced as /kemist/

chief pronounced as /či:fl

chef pronounced as /šef/

The "ch" letters in all the three words are pronounced differently.

5. The Model: The teacher may not be a good model with regard to the ay s/he speaks.

6. The Method: The teaching method may be at fault by overemphasizing one aspect of the language and neglecting the other.

7. The Materials: Materials which have teaching items sequenced in a certain way or which lack organization could lead to errors.

8. Inadequate Exposure to the Target Language: Students who live in a country where English is taught as a foreign language obviously do not have adequate exposure to the target language.

9. Overgeneralization: Overgeneralization covers instances where the learner creates a deviant structure on the basis of his experience of other structures in the target language.

10. Indeterminacy: It refers to an inconsistency or uncertainty in handling a linguistic item.

11. Medium Transfer: This is a term used by Tench (1983) for the learner's undue reliance on either the spoken or the written form of a word when the other medium is being used. If a pupil pronounces a word according to its spelling, then medium transfer has taken place (spelling pronunciation).

12. Communication Strategies: "A systematic technique employed by a speaker to express his meaning when faced with some difficulty" because of his "inadequate command of the language used in the interaction." (Corder, 1981, p. 103, cited in Mohideen). Some of these strategies are as follow:

a) Avoidance: Learner's avoidance leads to replacement of erroneous items.

b) Prefabricated patterns

c) Appeal to authority

d) Approximation 
e) Word coinage

f) Circumlocution

g) Language switch

\section{RESULTS AND DISCUSSIONS}

The results indicated that Persian learners who are learning English may encounter with lots of difficulties learning English spelling as it is represented the language at two levels at the same time, the level of units of meaning and the level of sounds. The sounds in the words do not correspond to their representative letters. On the other hand, English learners have to learn a completely new writing system as Persian is non-Roman language. Moreover, the results maintain the fact that English spelling is not purely 'phonetic'. If 'regularity' is defined as a direct and invariable one-toone correspondence between symbol and sound, then it is not completely regular. But regularity can be looked at in another way- the regular and unique representation of any of the units of a language. Furthermore, it illustrated the fact that Persian has a regular spelling system in the sense of one-to-one correspondence between sound and symbol. Therefore, based on the results of the comparison proper stage, it can be concluded that Persian learners may face spelling problems in the following areas:

- When one sound is represented by more than one letter as in /s/ and w, ص ث .

- The symbols which are considered as a base for short vowels and do not have the sound value in themselves as in قائم.

- Some letters are written but have no sound value as in خواهر.

- Short vowels are written and they should be guessed in context.

Also, English learners may have spelling difficulties in following parts:

- Some letters are written but have no sound value, e.g. brought.

- There is not much correspondence between the sounds and their representative letters, e.g. rough.

- Silent letters, e.g. sign, know.

- Sounds which have various letters and letter combinations in different contexts such as /f/ in fish and rough.

- One vowel sound can have different written forms: /ey/ in rain, may, etc.

One of the strategies which have been taken into account with regard to coping with such problematic areas deals with "Phonics" and "Phonograms." Phonics is a method for teaching English spelling which exploits various factors: (a) what regularities there are in the English spelling system; (b) what is known about how children handle reading and writing cognitively (for instance, that children may not have mastered certain sounds upon beginning reading instruction, and that they focus more strongly on the beginnings of words than the ends). Phonics proceeds in a sequence intended to make the complex subregularities of English spelling easier to handle for both student and teacher. Phonics must be distinguished from phonetics/phonology, which is a scientific attempt to analyze the English sound system, not its spelling system. Phonics does not strive so much for scientific accuracy as it does for finding regularity in the system for representing sounds with letters, and presenting those regularities in a scope and sequence that make it easier for a learner to master. Therefore many of its practices, such as distinguishing long from short vowels, are not phonologically accurate (length does not differentiate English vowel phonemes from one another; tongue height does). There was a time in the English language (ca. A.D. 500 to around A.D. 1500) when length did differentiate vowel phonemes, and the spelling system indicated this. But because English pronunciation continued to change after its spelling system became relatively fixed from 1200 to 1500 A.D., the spelling reflects the earlier period of English pronunciation. The phonics description of English spelling reflects the pronunciation of English in $1300 \mathrm{CE}$ more accurately than it does today's pronunciation.

Finally, in the last stage of the study, i.e. the prediction stage, some certain deviant phonological structures and pronunciation errors, which were expected to be produced by the three EFL learners, were analyzed meticulously in order to find the sources of such sound-spelling problems. Having a look at the lists of the sources of pronunciation problems of these Persian learners of English, we notice that the three factors of 'The Model', 'The Method', and 'Inadequate Exposure to the Target Language' are present in the diagnosis of almost all of them. This fact can lead us to one of the most important results that can be taken from this research; that is, in a country like Iran where English is considered as a foreign language, the teacher, the method, and the educational atmosphere play vital roles in teaching this language. In other words, since Persian learners of English are out of contact with native speakers, teachers, methods, and educational systems are responsible for bridging this gap.

'Mother Tongue Interference' and 'Overgeneralization' are two other important factors observed frequently among the sources of the problems. 'Mother Tongue Interference' mostly appeared in the shape of non-existent linguistic items; that is items which exist in English but not in Persian. This shows that the influence of non-existent linguistic items on the emergence of pronunciation problems overweighs the influence of negative and positive transfer from the L1.

Another point which is worth mentioning here is that by comparing the problems in different parts of the sample, we notice that performance lapses are more visible in the summary and reading aloud sample. For example, the learners can easily produce $/ \mathrm{w} /, / \mathrm{y} /$, and $/ \theta /$ sounds respectively in 'watched', 'interesting', and 'thin' when they are pronounced in isolation. But when it comes to producing the same words or words containing these sounds in either spoken or written 
contexts, the learners produce those Persian sounds which are 'close enough' and easier for them to produce. Therefore, they pronounce $/ \mathrm{w} /, / \mathrm{y} /$, and $/ \theta /$ as $/ \mathrm{v} /, / \mathrm{ng} /$, and $/ \mathrm{t} / \mathrm{respectively.}$

As Kenworthy (1990) argues, those problems that are vital for intelligibility and their occurrence impedes communication, need to be given high priority. In general, the areas of rhythm, word stress, and sentence stress are high priority areas for all learners. Other problems which do not affect intelligibility can be given low priority. The last groups of problems are those which, may contribute to a very noticeable foreign accent, will usually do not lead to intelligibility problems. This group can be given optional attention.

For Persian speakers of English, the priorities could be as follow:

High Priorities

1. Rhythm

2. Sentence stress

3. Word stress

4. Consonant clusters and sequences as in 'stop'.

5. Problems with vowels which do not exist in Persian and their mispronunciation causes confusion. Examples are

- /I/ in 'ship' which could be pronounced as /i:/ in 'sheep', and

- /^/, /a:/, /o:/ in 'cut', 'cot', 'caught' that if are used interchangeably, can cause difficulty.

6. Problems with consonants which do not exist in Persian and their mispronunciation causes confusion. For example $/ \theta /$ in 'thick' which might be pronounced as $/ \mathrm{s} /$ in 'sick'.

7. Intonation, especially in tag questions.

Low Priorities

1. Sounds which are slightly different in Persian and English, like /r/, /1/, /y/, etc.

2. Diphthongs

Optional Attention

1. Linkage in connected speech

2. /ð/ as in 'that'

\section{CONCLUSION}

As for the first research question, the Persian sound-spelling system was described in detail. Also, as the answer to the second question, the English sound-spelling system was described fully. Therefore, the first section of the study dealt with the description stage of contrastive studies in general. According to the description stage, the study concluded that different languages have different orthographic systems; some of them are more similar such as Roman alphabet in languages like English, German, and French. The others have much greater difference in writing system such as Roman vs. non-Roman as in Arabic and Persian. Therefore, the description section of the study indicates that all the languages, including Persian and English, are rule-governed in terms of spelling along with a number of exceptions. Learning the rules with their exceptions can decrease misspelling. Reading in context can be helpful in diagnosing the meaning. But yet, there are some irregular words that just can be internalized by rote learning.

Moreover, in order to answer the third research question, the juxtaposition and comparison stages were performed in which, firstly, those comparable features were identified and then the comparison proper was done.

On the basis of the results of the comparison proper, the study concluded that the Iranian EFL learners as well as teachers must take these features into account, so that they do not face any sound-spelling problems. Furthermore, with regard to English learners of Persian language, the study concluded some sound-spelling features that they may encounter with.

Finally, regarding the last research question related to the prediction stage of the present contrastive study, it was concluded that the sources of the pronunciation problems of Persian learners of English as a foreign language mainly lie in the pedagogical system through which this language is taught. Factors like 'Mother Tongue Interference' and 'Overgeneralization' certainly result in pronunciation problems but when it come to teaching English in a country like Iran, where it is considered as a foreign language, other factors such as 'The Model', 'The Method', and 'Inadequate Exposure to the Target Language' will become more perceptible as the sources of pronunciation problems. Since intelligibility is the most sensible goal of pronunciation, problems like those which occur in the areas of rhythm, word stress, and sentence stress, and those problems with vowels, consonants, consonant clusters, and intonation which interfere with the process of communication and cause unintelligibility should be given a higher priority than the others. To avoid pronunciation problems, both learners and particularly teachers should expose themselves to the target language as much as possible through the mass media. Teachers should create an English atmosphere in which learners are able to think in English.

\section{Pedagogical IMPLiCATIONS}

According to the results of the present study, the following implications are drawn in the form of a trouble-shooting manual to reduce the number of pronunciation problems committed by our Persian learners of English as a foreign language: 
1. Students should be advised to listen to good English from what available source_radio, television, native speakers, and good local speakers of the language. They should listen for correct pronunciation and understanding.

2. Students can record their speech, compare it to that of a native speaker in terms of vowels, consonants, consonant clusters, stress, intonation, etc., find their problems in each area, and practice the correct pronunciation.

3. Teachers must frequently remind their students that when they speak in English, they must think in the target language so that they do not bring in any feature of their mother tongue.

4. English is not an easy language to master. Teachers of English should advise their students to persevere in studying English. There are no short cuts to learning the language. When they are sufficiently exposed to target language, the possibility of making pronunciation errors is minimized.

5. Teachers need to keep themselves abreast of current issues by reading books and journals related to our profession.

6. Teachers should make sure that there is all round language development. They should not spend too much time on one area of language to the detriment of others.

7. Teachers should encourage students to speak in English with their fellow students in school or on campus and create an atmosphere in class that is conductive to learning the language.

8. The teacher should provide an explanation with regard to the possible source or cause of error to bring about an awareness of what could be the potential contributory factor.

\section{REFERENCES}

[1] Arab-Moghaddam, N. and Senechal, M. (2001). Orthographic and phonological processing skills in reading in Persian/English bilinguals. International Journal of Behavioral Development, 25, 140-147.

[2] Bloemsaat, J. G., Van Galen, G. P., \& Meulenbroek, R. G. J. (2003). Lateralized effects of orthographical irregularity and auditory memory load on the kinematics of transciption typewriting. Psychological Research, 67(2), 123-133.

[3] Caramazza, A., \& Miceli, G. (1990). The structure of graphemic representations. Cognition, 37, 243-297.

[4] Chastain, K. (Eds.). (1988). Developing Second-Language Skills. Florida: Harcourt Brace Jovanovich, Inc.

[5] Chomsky, N. (1965). Aspects of the theory of syntax. Cambridge, MA: MIT Press. Contrastive Analysis: Euphemisms in English and Vietnamese with DEATH retrieved from http://web.hanu.vn/en/file.php/1/moddata/forum/70/671/01__euphamismthay_Thien.doc.

[6] Crystal, D. (1985). A dictionary of linguistics and phonetics. 2nd. edition. Oxford: Blackwell.

[7] Derwing, T. M., \& Munro, M. J. (September 2005). Second Language Accent and Pronunciation Teaching: A Research-Based Approach. TESOL QUARTERLY, Vol. 39, No. 3, pp. 379-396.

[8] Ellis, A. W. (1982). Spelling and writing (and reading and speaking). In A. W. Ellis (Ed.), Normality and pathology in cognitive functions (pp. 113-146). New York: Academic Press.

[9] Ellis,A. W. (1984). Spelling and writing. In A.W. Ellis (Ed.), Reading, writing and dyslexia: A cognitive analysis (pp. 60-85). Hillsdale, NJ: Erlbaum.

[10] Farooq, M. U. (1998). Contrastive and Error Analysis Based Teaching Strategies. Aichi Women's Junior College.

[11] Fisiak, J. (1981). Contrastive Linguistic \& The Language Teacher. Pergamon press Ltd.

[12] Frith, U. (1986). A developmental framework for developmental dyslexia. Annals of Dyslexia (36), 69-81.

[13] Hanna, P.R., J.s. Hnna, R.E. Hodges \& E.H. Rudorf (1966). Phoneme-garpheme correspondence as cues to spelling improvement. Washington. DC: U.S. Department of Health, Education and Welfare.

[14] Kandel, S., Alvarez, C. J., \& Vallée, N. (submitted). (2006). Syllables as processing units in handwriting production.

[15] Kenworthy, J. (1990). Teaching English Pronunciation. The United States of America: Longman Inc.

[16] Khanlari, P.N. (1979).The history of the Persian Language (vol.1).New Delihi: New Pehli Press.

[17] Lado, R. (1995). Linguistics Across Culture: Applied Linguistics for Language Teacher.

[18] Meulenbroek, R. G. J., \& Van Galen, G. P. (1990). Perceptual-motor complexity of printed and cursive letters. Journal of Experimental Education, 58, 95-110.

[19] Mohideen, H. (1996). ERROR ANALYSIS- Contributory Factors to Student' Errors, with Special Reference to Errors in Written English. The English Teacher, Vol. xxv.

[20] Mojet, W. (1991). Characteristics of developing handwriting skills in elementary education. In W. J. \& W. A. M. \& N. Sovik (Eds.), Development of graphic skills (pp. 53-75). London: Academic Press.

[21] O'Connor, J. D. (1989). Sounds English. UK: Longman Group UK Limited.

[22] Orliaguet, J. P., Zesiger, P., Boë, L. J., \& Mounoud, P. (1993). Effects of phonetics on handwriting production: Analysis of reaction time and movement velocity. Paper presented at the Sixth International Conference on Handwriting and Drawing, Paris.

[23] Perfetti, C. A. (1992). The representation problem in reading acquisition. In P. Gough \& L. C. Ehri \& R. Treiman (Eds.), Reading acquisition (pp. 145-174). Hillsdale, N.J.: Lawrence Erlbaum Associates.

[24] Rabiner, L. R., \& Gold, B. (1975). Theory and application of digital signal processing. N.J.: Prentice-Hall.

[25] Richards, J.C., Platt, J. \& Platt, H. (Eds.). (1992). Longman Dictionary of Language Teaching and Applied Linguistics. UK: Longman Group UK Limited.

[26] Roach, P. (Eds.). (2000). English Phonetics and Phonology. Cambridge: The Press Syndicate of the University of Cambridge.

[27] Seidenberg, M. S., \& Waters, G. S. (1985). Spelling-sound effects in reading: Time-course and decision criteria. Memory and Cognition, 13(6), 557-572.

[28] Sénéchal, M. (2000). Morphological effects in children's spelling of French words. Canadian Journal of Experimental Psychology, 54, 76-86.

[29] Setter, J. and J. Jenkins. (2005). Pronunciation. Language Teaching, 38/1: 1-17. 
[30] Share, D. L. (1999). Phonological recoding and orthographic learning: A direct test of the self-teaching hypothesis. Journal of Experimental Child Psychology, 72, 95-129.

[31] Share, D. L. (2008). Orthographic learning, phonological recoding, and self-teaching. In R. Kail (Ed.). Advances in child development and behavior (vol. 36, pp. 31-82). San Diego: Academic Press.

[32] Sprenger-Charolles, L., Siegel, L., Béchennec, D., \& Serniclaes, W. (2003). Development of phonological and orthographic processing in reading aloud, in silent reading, and in spelling: A four-year longitudinal study. Journal of Experimental Child Psychology, 84, 194-217.

[33] Stanovich, K. E., \& West, R. F. (1989). Exposure to print and orthographic processing. Reading Research Quarterly, 21, 402433.

[34] Tench, P. (1981). Pronunciation Skills. London: The Macmillan Press (Essential Language Teaching Series).

[35] Teulings, H. L., Thomassen, A. J. W. M., \& Van Galen, G. P. (1983). Preparation of partly precued handwriting movements: The size of movement units in handwriting. Acta Psychologica, 54, 165-177.

[36] Waters, G. S., Bruck, M., \& Seidenberg, G. (1985). Do children use similar processes to read and spell? Journal of Experimental Child Psychology, 39, 293-305.

[37] Wing, A. (1980). The height of handwriting. Acta Psychologica(82), 353-365.

[38] Wing, A. M., \& Baddeley, A. D. (1980). Spelling errors in handwriting: A corpus and a distributional analysis. In U. Frith (Ed.), Cognitive processes in spelling. London: Academic Press.

[39] Yarmohammadi, L. (2000). A Contrastive Phonological Analysis of English and Persian. Shiraz: Shiraz University Press.

[40] Yarmohammadi, L. (2002). A Contrastive Analysis of Persian and English: Grammar, Vocabulary and Phonology. Tehran: Payame Noor University Press.

[41] Zesiger, P., Mounoud, P., \& Hauert, C. A. (1993). Effects of lexicality and trigram frequency on handwriting production in children and adults. Acta Psychologica, 82, 353-365.

Seyyed Mohammad Ali soozandehfar was born in 1985 in Shiraz, Iran. He got his BA in English Language and Literature, and received his MA in TEFL both from Shiraz University, Shiraz, Iran. Now, he is a Ph.D. candidate in TEFL.

He works in different language institutes as Teacher, Researcher, Translator, and Instructor on English language. He has 7 years of job experience. Also, he has taught some MA preparatory courses at Shiraz University.

Mr. Soozandehfar has been a top student both in BA and MA.

Marzieh Souzandehfar was born in 1981 in Shiraz, Iran. She got her BA in English Language and Literature, and received her MA in TEFL both from Shiraz University, Shiraz, Iran. Now, she is a Ph.D. candidate in TEFL, and is Shiraz University and Zarqan Azad University Instructor.

Ms. Souzandehfar has been a top student both in BA and MA. 